\title{
The Effects of Technology on Diversity or When is Diversity Not Diversity?
}

\author{
Arthur T. Johnson, Rosemary L. Parker \\ University of Maryland
}

The University of Maryland campus community is proud of its diverse student body. It is a campus where diversity is celebrated and nurtured, even defended before the U. S. Supreme Court. The University has invested heavily in building and maintaining a student body consisting of 12\% African Americans, 13\% Asian Americans, 5\% Hispanic, and 4\% of international origin.

The mission of the University of Maryland Diversity Initiative is to build a more inclusive community grounded in respect of differences based on age, race, ethnicity, gender, religion, disability, sexual orientation, class, marital status, political affiliation, and national origin. The presumption, then, is that if minority student enrollment increases, so does cultural diversity. However, there may be other factors that dilute the value to the campus of diversity based mostly on race affiliation.

Admissions standards at the University of Maryland have markedly increased in recent years (for example, in 1992 the average SAT score of the incoming freshmen was 1068 with a high school GPA of 3.19; corresponding statistics in 2000 are 1253 and 3.74). Imposition of these standards has resulted in cultural, as well as academic, selection. There is a much smaller difference among racially diverse students because we are now selecting from among applicants with similar backgrounds.

One of the factors that seem to be having a profound effect on the diversity of our student body is technology. Seventy-three percent of white pre-college students and $32 \%$ of African American students have computers at home. These same students are likely to have other technology (cell phones and pagers), strongly supportive parents, more than adequate family income, stable home life, and encouragement for extra curricular activities. Culturally, these students are relatively homogenous, and the technology found in their homes are standardizing the thought processes of these human beings. As we have become a more selective institution, we have sought out those students who are more technology privileged but perhaps less imaginative and creative. As we strive to select the top ten students, it is important to consider many factors so that we may have a campus that is culturally and creatively diverse as well as diverse racially and ethnically.

The effects of all this are seen in several places. The Banneker-Key scholarship is the most prestigious and selective all expenses paid scholarship at the University of Maryland. From an annual pool of 20,000 freshman applicants to the University, only 2000 applications folders are reviewed for this purpose, and only 105 students actually receive the Banneker-Key scholarship. Opinions of members of the Banneker-Key scholarship committee is that there is less creativity, imagination, and originality evident in the application materials than there once was. There are

\footnotetext{
"Proceedings of the 2001 American Society for Engineering Education Annual Conference \& Exposition Copyright Ó 2001, American Society for Engineering Education"
} 
other indicators of homogeneity: out of 28 randomly-selected applications materials, there were 11 females and 17 males, with average SAT scores of 1452 and average high school GPA of 4.25 (weighted). Six of these were first generation college applicants, two were children of parents one of whom had attained a bachelor's degree or higher, and 20 had two parents with college degrees. There were 12 who listed themselves as Caucasian, 7 as African American, 8 as Asian, and 1 as Hispanic. Of the 28 folders, 25 had given email addresses. The faces of the students in a class may look different, buy once they open their mouths, their voices all sound the same.

A Cultural Diversity Survey was conducted among 57 Sophomores, Juniors, and Seniors in the Biological Resources Engineering program at the University of Maryland. This program is among the most diverse at the university, but there was no attempt to select students to receive the questionnaire except that they were enrolled in either a required sophomore, junior, or senior level course in the spring semester 2000. Of the respondents, 23 were male and 34 female. Two were African Americans, 10 Asian Americans, 35 European Americans, and 6 were of other ethnicity, including Hispanic. The remainder didn't respond to this question. Their average ages were $21.3 \pm 1.81$ (mean \pm std. deviation). The 57 respondents were asked which of these technologies they had available before coming to the University of Maryland: Television (56), Radio (56), Computer (54), Video Cassette Recorder (55), Cellular Phone (26), Pager (20), and Compact Disk Player (53).

They were asked to rate their agreement with the following statements on a scale of 1 (least agreement) to 5 (most agreement). They were told to base their answers on the years immediately preceding their entrances into the University of Maryland.

$4.70 \pm 0.462$ I was a good student.

$4.14 \pm 1.11$ The atmosphere at home was conducive to study.

$4.61 \pm 0.726$ My family supported me and encouraged academic achievement.

$4.12 \pm 1.15$ I used the computer a lot.

$3.23 \pm 1.30 \quad$ My cultural experience was different from the experiences of my classmates in college.

When asked to rank activities by the amount of time spent on each before coming to the University of Maryland, they responded with:

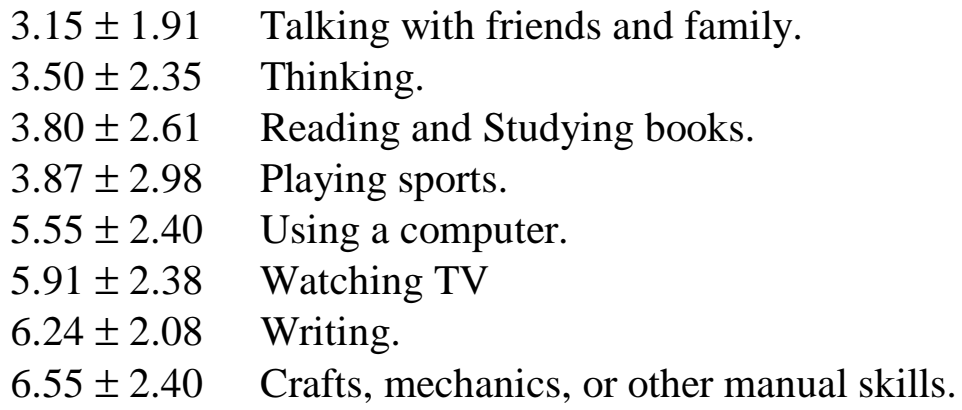

"Proceedings of the 2001 American Society for Engineering Education Annual Conference \& Exposition Copyright Ó 2001, American Society for Engineering Education” 


\section{$6.85 \pm 2.64 \quad$ Volunteer work.}

$7.72 \pm 2.62$ Playing a musical instrument.

Numbers denote average ordinal responses with standard deviations.

What emerges from the results of this study is a student body with a self-image more diverse than is indicated by the academic atmosphere, available technology, and activities that they engaged in. Despite the varied ethnic backgrounds of these students, they appeared to have very parallel and homogeneous lives before matriculation at the University of Maryland.

The data thus far supports the conclusion that as entrance requirements increase, cultural diversity of students decrease. We attempted to find some performance measures that would reflect the effects of higher entrance requirements and the cultural meanings of those requirements. In Table I are found retention rates for students in the University of Maryland Honors program, and in Table II are found retention rates for students at the other end of the academic spectrum. Retention rates and the 4-year graduation rate for the class of 1999 are all higher for the Honors students than for students not part of Honors or similar programs. This would be expected, because Honors students have the advantages of better academic records, more scholarships, probably more supportive families and friends, and access to technologies, as already discussed.

The differences between retention rates and graduation rates of the two student groups widens as time goes on. Nearly $60 \%$ of the Honors students graduated in 4 years compared to $30 \%$ of the non-Honors students.

Comparing African American students to their respective groups shows that African Americans had lower 4 year graduation rates than the averages for both student groups. However, the graduation rate of African American students was 70\% of the average for the Honors students, but less than $50 \%$ of the average for the non-Honors students. A somewhat similar trend can be seen for Hispanic students, but not for Caucasian or Asian students.

We conclude from this that better students are more likely to be retained at the University and to graduate in 4 years. Therefore, the advantage of raising entrance requirements has positive academic rewards for the University.

It could be asked, "why is diversity among students a desirable goal?" Is this just an example of social engineering, or is there a real educational benefit to diversity in the classroom? The concept of the traditional university, wherein students learn by immersion in an intellectual atmosphere of new ideas and by exposure to experiences of a multifarious nature, is enhanced by a diverse student body. Teaching in the classroom is enriched by student experiences shared with other students. Core technical material is perhaps independent of culture, but applications are not. A classroom full of students representing different cultures yields learning benefits well beyond material that appears in textbooks.

\footnotetext{
"Proceedings of the 2001 American Society for Engineering Education Annual Conference \& Exposition Copyright Ó 2001, American Society for Engineering Education”
} 
There are pressures to transform the university from a place of quiet intellectual pursuit into a competitive atmosphere of energy and vitality. These modern universities scramble to climb to the "top ten", and once there, to become "number one". In the quest of competitive position, real cultural diversity is sacrificed for higher SAT scores and Grade Point Averages. As these universities become more selective, admitted students seem to become more homogeneous. What is left of diversity are the vestiges of skin colors and surnames. The cultural richness that they once would have brought to the classroom has become a relative sameness. All this in the name of quality.

There are good reasons for selecting students with the highest SAT scores. These students learn fast and perform well. They are not only easy to teach, but they become an object of pride. However, the price paid for extreme selectivity is a constriction of cultural diversity. As SAT scores homogenize, so do the students.

The University of Maryland has been proud of its record on diversity, but Chaucer said, "if the gold rusts, what of the iron?" Indeed, if the University of Maryland, which has placed so much emphasis on diversity, is in danger of eradicating true diversity as it becomes more selective, what of those universities for which diversity is less important?

There is no answer to this question. Just as every engineering design involves trade-offs, so does the choice between true cultural diversity and selectivity. We conclude, however, that diversity is often not what it appears to be. The true diversity of students who have met or exceeded high admissions standards often does not enhance the academic environment in the way it could have. This diversity is dishonest diversity; it is a fraud.

The most imaginative and creative minds may not always have the highest standardized test scores or have access to the latest in technology. For example, through the individual admissions program, the University is able to bring in truly different students. Many of these admissions have talents, such as athletic or artistic performance, that normally would not qualify them to come to the University of Maryland. However, these students are not likely to fit the same experiential and cultural mold as those who qualify for regular academic admission. This is diversity for real; diversity that broadens the collective experience of faculty and students at the University.

We certainly do not want to lower admissions standards and recent achievements of the University of Maryland, but we do want to enhance student experiences through opportunities given to students who represent real differences in creativity, imagination, and originality.

In an article on admissions decisions, Arthur Coleman, Deputy assistant Secretary, U.S. Dept. of Education, challenged us to think of Admissions this way: "You are a conductor of an orchestra. You may hire five additional musicians before your fall tour. Of the twenty candidates who have applied, the five most musically-credentialed candidates are all violinists. Do you hire only violinists when you have broader musical needs?" Clearly it is not enough to hire five violinists of different racial and ethnic backgrounds. Likewise on our campus we need students from

"Proceedings of the 2001 American Society for Engineering Education Annual Conference \& Exposition Copyright Ó 2001, American Society for Engineering Education” 
different racial and ethnic backgrounds who bring different creative and intellectual talents to the campus community.

Table I. Percent Retention Rates for Students in the University of Maryland Honors Program (1999 data).

\begin{tabular}{cccccc} 
Year & \multicolumn{5}{c}{ Race } \\
\cline { 2 - 5 } 1995 (matriculated) & All & Afr. Amer. & Hisp. & Cauc. & Asian \\
1996 & 96.2 & 98.0 & 90.7 & 96.6 & 95.8 \\
1997 & 89.5 & 90.2 & 83.7 & 89.0 & 94.7 \\
1998 & 88.4 & 88.2 & 79.1 & 88.4 & 92.6 \\
1999 (graduated) & 58.6 & 41.2 & 48.8 & 61.2 & 60.0 \\
1996 (matriculated) & & & & & \\
1997 & 94.7 & 95.1 & 93.3 & 94.3 & 97.0 \\
1998 & 91.5 & 92.2 & 93.3 & 90.9 & 93.0 \\
1999 & 90.3 & 91.2 & 88.98 & 89.7 & 94.0 \\
1997 (matriculated) & & & & & 97.1 \\
1998 & 96.0 & 93.9 & 95.9 & 95.6 & 90.4 \\
1999 & 90.9 & 87.9 & 85.7 & 91.5 & \\
1998 (matriculated) & & & & & \\
1999 & 95.7 & 89.7 & 89.2 & 96.4 & 98.0 \\
\hline
\end{tabular}

"Proceedings of the 2001 American Society for Engineering Education Annual Conference \& Exposition Copyright Ó 2001, American Society for Engineering Education" 
Table II. Percent Retention Rates for Students of the University of Maryland Who Are Not in Honors or Similar Programs (1999 data).

\begin{tabular}{cccccc} 
Year & \multicolumn{5}{c}{ Race } \\
\cline { 2 - 6 } 1995 (matriculated) & All & Afr. Amer. & Hisp. & Cauc. & Asian \\
1996 & 83.6 & 82.1 & 86.2 & 83.3 & 87.3 \\
1997 & 72.1 & 65.7 & 73.1 & 72.8 & 77.5 \\
1998 & 68.5 & 58.0 & 67.7 & 70.6 & 72.6 \\
1999 (graduated) & 30.3 & 14.2 & 15.4 & 37.1 & 26.4 \\
1996 (matriculated) & & & & & \\
1997 & 83.8 & 80.0 & 77.8 & 84.7 & 89.3 \\
1998 & 73.6 & 68.5 & 70.6 & 74.3 & 82.1 \\
1999 & 68.7 & 60.5 & 65.9 & 70.2 & 78.2 \\
& & & & & \\
1997 (matriculated) & & & & & \\
1998 & 84.7 & 83.2 & 76.9 & 84.9 & 89.8 \\
1999 & 75.5 & 71.4 & 61.2 & 77.1 & \\
1998 (matriculated) & & & & & 91.9 \\
1999 & 88.4 & 81.8 & 85.8 & 88.2 &
\end{tabular}

\section{ARTHUR T. JOHNSON}

Arthur T. Johnson is currently Professor in Biological Resources Engineering at the University of Maryland. He has been active in bioengineering, holding major offices in several societies such as AIMBE, AEMB, ASAE, NABEC, IBE, and ISRP. He is a Fellow of ASEE and AIMBE. He received his B.A.E. degree in 1964, M.S. degree in 1967, and his Ph.D. degree in 1969, all from Cornell University.

\section{ROSEMARY L. PARKER}

Rosemary L. Parker is the Director of the Center for Minorities in Science and Engineering in the A.J. Clark School of Engineering, University of Maryland, College Park. She received her A.B. in Psychology from Lafayette College, Easton, PA (1977) and her M.S. in Counseling from the State University of New York at Oswego (1979). She has received numerous awards for her work at Maryland.

\footnotetext{
"Proceedings of the 2001 American Society for Engineering Education Annual Conference \& Exposition Copyright Ó 2001, American Society for Engineering Education"
} 